\title{
Surface Charges of the Membrane Crucially Affect Regulation of Na,K-ATPase by Phospholemman (FXYD1)
}

\author{
Erica Cirri • Corinna Kirchner • Simon Becker • \\ Adriana Katz • Steven J. Karlish • Hans-Jürgen Apell
}

\begin{abstract}
The human $\alpha_{1} / \mathrm{His}_{10}-\beta_{1}$ isoform of Na,K-ATPase has been reconstituted as a complex with and without FXYD1 into proteoliposomes of various lipid compositions in order to study the effect of the regulatory subunit on the half-saturating $\mathrm{Na}^{+}$concentration $\left(K_{1 / 2}\right)$ of $\mathrm{Na}^{+}$ions for activation of the ion pump. It has been shown that the fraction of negatively charged lipid in the bilayer crucially affects the regulatory properties. At low concentrations of the negatively charged lipid DOPS ( $<10 \%$ ), FXYD1 increases $K_{1 / 2}$ of $\mathrm{Na}^{+}$ions for activation of the ion pump. Phosphorylation of FXYD1 by protein kinase A at Ser68 abrogates this effect. Conversely, for proteoliposomes made with high concentrations of DOPS $(>10 \%)$, little or no effect of FXYD1 on the $K_{1 / 2}$ of $\mathrm{Na}^{+}$ions is observed. Depending on ionic strength and lipid composition of the proteoliposomes, FXYD1 can alter the $K_{1 / 2}$ of $\mathrm{Na}^{+}$ions by up to twofold. We propose possible molecular mechanisms to explain the regulatory effects of FXYD1 and the influence of charged lipid and protein phosphorylation. In particular, the positively charged
\end{abstract}

Electronic supplementary material The online version of this article (doi:10.1007/s00232 0139600 5) contains supplementary material, which is available to authorized users.

E. Cirri · C. Kirchner · S. Becker · H. J. Apell ( $₫)$

Department of Biology and Graduate School of Chemical Biology, University of Konstanz, 78464 Constance, Germany

e mail: h j.apell@uni konstanz.de

\section{Present Address:}

E. Cirri

Molecular Mechanisms of Membrane Transport Laboratory, Institut Pasteur, 25 rue du Docteur Roux, 75724 Paris Cedex 15, France

A. Katz · S. J. Karlish

Department of Biological Chemistry, Weizmann Institute of Science, 76100 Rehovot, Israel
C-terminal helix of FXYD1 appears to be highly mobile and may interact with the cytoplasmic $\mathrm{N}$ domain of the $\alpha$-subunit, the interaction being strongly affected by phosphorylation at Ser68 and the surface charge of the membrane.

Keywords Sodium pump - Regulation - Transport kinetics $\cdot$ Sodium binding $\cdot$ Electrogenicity $\cdot$ Protein protein interaction

\section{Introduction}

$\mathrm{Na}, \mathrm{K}-\mathrm{ATPase}$ is an integral membrane protein present in virtually all animal cells, where it transports $\mathrm{Na}^{+}$and $\mathrm{K}^{+}$ ions across the plasma membrane against their electrochemical potential gradients. For every ATP molecule hydrolyzed, the enzyme pumps three $\mathrm{Na}^{+}$ions out of and two $\mathrm{K}^{+}$ions into the cell. Because of its fundamental role in cell physiology, Na,K-ATPase is the target of several specific regulatory mechanisms. Among them, the enzyme is modulated in various cells by interaction with the socalled FXYD proteins, a group of short, single-transmembrane proteins named after the invariant extracellular motif FXYD (Garty and Karlish 2006; Geering 2006; Sweadner and Rael 2000). All mammalian members of the FXYD family are known to associate with $\mathrm{Na}, \mathrm{K}$-ATPase and modulate its properties in a tissue- and isoform-specific way. FXYD1, also known as phospholemman, was first identified as the major substrate for protein kinases $\mathrm{A}$ (PKA) and C (PKC) in the heart (Palmer et al. 1991; Presti et al. 1985b). Subsequently, it has been found to associate with specific isoforms of $\mathrm{Na}, \mathrm{K}$-ATPase and modulate the enzyme activity in heart and skeletal muscle as well as kidneys and brain (Feschenko et al. 2003; Floyd et al. 2010). 
So far, the effects of FXYD1 on Na,K-ATPase have been investigated mostly in intact cells, both native and heterologous expression systems. These systems allow characterization of the physiological effects of FXYD1 but are of limited use for detailed study of functional and structural interactions between FXYD1 and the enzyme. Recently, a purification procedure of the human $\alpha_{1} / \mathrm{His}_{10^{-}}$ $\beta_{1}, \alpha_{2} / \mathrm{His}_{10}-\beta_{1}$ and $\alpha_{3} / \mathrm{His}_{10}-\beta_{1}$ isoforms of $\mathrm{Na}, \mathrm{K}$-ATPase expressed in yeast Pichia pastoris has been developed and introduced for mechanistic studies (Cohen et al. 2005; Haviv et al. 2007; Katz et al. 2010). The purified, detergent-solubilized $\alpha_{1} / \mathrm{His}_{10}-\beta_{1}$ can be reconstituted in vitro with purified, detergent-solubilized human FXYD1 expressed in Escherichia coli to obtain the $\alpha_{1} / \mathrm{His}_{10}-\beta_{1} /$ FXYD1 complex (Cirri et al. 2011; Lifshitz et al. 2006; Mishra et al. 2011). The purified recombinant proteins provide a preparation that enables us to work under welldefined conditions, controlling the stoichiometry of FXY$\mathrm{D}: \alpha \beta$ complexes and without interference by other cellular components. Unlike the situation with native cells, the effects of FXYD1 on the different isoforms of $\mathrm{Na}, \mathrm{K}$ ATPase can be investigated separately. Moreover, since the phosphorylation state of FXYD1 in the purified preparations is easily controllable, the functional role of the protein kinase-mediated phosphorylation of FXYD1 can be studied. Therefore, these systems allow a detailed functional analysis of the effects of FXYD1 on Na,K-ATPase.

In recent studies, purified recombinant proteins have been exploited to investigate the effect of FXYD1 on various partial reactions of the Post-Albers cycle of Na,K-ATPase (Cirri et al. 2011; Lifshitz et al. 2006). In these preparations, the presence of FXYD1 affects only the $\mathrm{Na}^{+}$binding and release kinetics in both principal conformations, $E_{1}$ and $\mathrm{P}^{-E_{2}}$. All other partial reactions of the pump cycle, such as $\mathrm{K}^{+}$binding and release, enzyme phosphorylation and dephosphorylation and conformation transitions, are not significantly modified by FXYD1 (Cirri et al. 2011). FXYD1 increased the apparent $\mathrm{Na}^{+}$-binding affinity in reconstituted complexes when measured directly using the electrochromic shift dye RH421 (Cirri et al. 2011). This is an intriguing finding because various studies in native membranes of different cells have shown that FXYD1 increases the halfsaturating $\mathrm{Na}^{+}$concentration $\left(K_{1 / 2}\right)$ of $\mathrm{Na}^{+}$ions for activation of the ion pump (Cornelius and Mahmmoud 2003; Crambert and Geering 2003; Garty and Karlish 2006; Geering et al. 2003; Geering 2005, 2006, 2008). In purified recombinant proteins, an annulus of lipids and detergent molecules surrounds the hydrophobic part of the membrane helices and maintains the functional integrity of the enzyme. However, it does not provide the planar membrane surface present in cells, and potentially, this may affect the interaction between FXYD1 and Na,K-ATPase.
The structure of FXYD1 as a free monomer in SDS micelles was determined by NMR spectroscopy (Teriete et al. 2007). FXYD1 appears to be organized in four $\alpha$ helices: $\mathrm{H} 1$ at the extracellular side (Asp12 Gln17), H2 as a transmembrane domain (Ile18 Leu36) and on the cytoplasmic side H3 (Ser37 Lys43) and H4 (Thr59 Ser68). The FXYD motif forms a disordered segment preceding $\mathrm{H} 1$. Helices $\mathrm{H} 1, \mathrm{H} 2$ and $\mathrm{H} 3$ are rigidly connected and show similar backbone dynamics, while $\mathrm{H} 4$ is linked to the others by a long flexible loop. Both cytoplasmic helices, $\mathrm{H} 3$ and $\mathrm{H} 4$, are associated with the micelle surface so that, overall, FXYD1 adopts an L-shaped conformation. So far, this is the only complete structure available for an FXYD protein since in neither of the crystal structures of $\mathrm{Na}, \mathrm{K}$ ATPase published to date (Morth et al. 2007; Shinoda et al. 2009) were the cytoplasmic sequences of FXYD2 and FXYD10 resolved. The flexible stretch between $\mathrm{H} 3$ and $\mathrm{H} 4$ should allow great flexibility of the C-terminal domain of the FXYD proteins and could account for its absence in the $\mathrm{X}$-ray structures.

Solid-state NMR data of FXYD1 in lipid bilayers formed of 1,2-dioleoyl-sn-glycero-3-phosphocholine (DOPC) and 1,2-dioleoyl-sn-glycero-3-phosphoglyceol (DOPG) (DOPC/ DOPG 4:1) also indicate the association of these helices with the membrane (Franzin et al. 2007). Moreover, isothermal titration calorimetric experiments have shown that a 35-amino acid peptide representing the cytoplasmic sequence FXYD1 $1_{38-72}$ associates with the membrane depending on the amount of negatively charged phospholipids (Hughes et al. 2011). The presence of several basic residues in helices $\mathrm{H} 3$ and $\mathrm{H} 4$ explains their propensity to interact with the negatively charged surface of the SDS micelle and with lipid bilayers containing $25 \mathrm{~mol} \%$ or more of anionic phospholipids. However, such a disposition of $\mathrm{H} 4$ is unlikely to be a physiological one since this helix contains residues Ser63, Ser68 and Thr69, which are targets of PKA and PKC in vivo (Fuller et al. 2009; Palmer et al. 1991; Presti et al. 1985a, b; Walaas et al. 1994). Phosphorylation of these residues provides another mechanistic concept to regulate Na,K-ATPase by FXYD1. The presence of the (negatively charged) phosphates and the high mobility of $\mathrm{H} 4$ may lead in vivo to a modulated interaction of FXYD1 with the cytoplasmic domain of the ion pump.

In view of the considerations just raised, the presence and composition of a lipid bilayer surrounding the enzyme may be important for the correct interaction of FXYD1 with Na,K-ATPase. In order to investigate this aspect of the regulation of Na,K-ATPase by FXYD1, purified recombinant proteins were reconstituted in proteoliposomes and the activation of ion pumping by $\mathrm{Na}$ ions, in the absence and presence of FXYD1, was evaluated using proteoliposomes with specific lipid compositions. 


\section{Materials and Methods}

\section{Materials}

Bovine serum albumin (BSA) was obtained from Bio-Rad (Hercules, CA, USA) and nicotinamide adenine dinucleotide $(\mathrm{NADH})$ from Roche (Indianapolis, IN, USA). $n$-Dodecyl- $\beta$ maltoside (DDM) was purchased from Anatrace (Santa Clara, CA, USA) and BD-Talon metal affinity resin from Clontech (Mountain View, CA, USA). Octaethylene glycol monododecyl ether $\left(\mathrm{C}_{12} \mathrm{E}_{8}\right)$ was obtained from Bachem (Bubendorf, Switzerland) and 1-stearoyl-2-oleoyl-sn-glycero-3-(phospho1-serine) (SOPS), 1,2-dioleoyl-sn-glycero-3-phosphoglyceol (DOPS), 1,2-dierucoyl-sn-glycero-3-phosphocholine (DEPC), $\mathrm{L}-\alpha$-phosphatidylcholine from soybean (SBPC), 1,2-dipalmitoyl-sn-glycero-3-phosphocholine (DPPC) and 1,2-dioleoylsn-glycero-3-phosphoethanolamine (DOPE), from Avanti Polar Lipids (Alabaster, AL, USA). AcTEV ${ }^{\mathrm{TM}}$ Protease was from Life Technologies (Carlsbad, CA, USA). ATP (disodium salt, special quality) was obtained from Roche. The membrane potential-sensitive fluorescent dye bis-(3-propyl-5-oxoisoxazol-4-yl)pentamethine oxonol (oxonol VI) was ordered from MoBiTec (Goettingen, Germany). Recombinant cAMPdependent PKA (2,500,000 units $\mathrm{ml}^{-1}$, catalog no. P6000L), and calf intestinal alkaline phosphatase (CIP; 10,000 units $\mathrm{ml}^{-1}$, catalog no. M0290S) were obtained from Bio Labs (Lawrenceville, GA, USA). All other reagents were purchased from Merck (Darmstadt, Germany) or SigmaAldrich (St. Louis, MO, USA) at the highest quality available.

Methods

\section{Purification of Na,K-ATPase Expressed in P. pastoris}

The human $\alpha_{1} / \mathrm{His}_{10}-\beta_{1}$ isoform of $\mathrm{Na}, \mathrm{K}$-ATPase was expressed in $P$. pastoris as described previously, with a His $_{10}$ tag added to the $\mathrm{N}$ terminus of the $\beta$-subunit (Cohen et al. 2005). In short, the cells were broken with glass beads and urea-treated membranes were prepared. The membranes were solubilized with DDM (DDM:protein 2:1 $\mathrm{w} / \mathrm{w})$, and the human $\alpha_{1} / \mathrm{His}_{10}-\beta_{1}$ complex was purified by metal chelate chromatography with BD-Talon beads as described (Haviv et al. 2007; Lifshitz et al. 2007). Approximately $100 \mu \mathrm{g}$ of purified enzyme were obtained from $10 \mathrm{~g}$ of yeast cells. For further use the protein solution was concentrated to $0.71 .1 \mathrm{mg} \mathrm{ml}^{-1}$ protein with Amicon Ultra Centrifugal Filters $100 \mathrm{~K}$ (Millipore, Billerica, MA; exclusion size $100 \mathrm{kDa}$ ) in a buffer of $20 \mathrm{mM}$ tricine $(\mathrm{pH}$ 7.4) and $25 \%$ glycerol, and stored at $0{ }^{\circ} \mathrm{C}$ (for short periods) or at $80^{\circ} \mathrm{C}$ after freezing with liquid $\mathrm{N}_{2}$. The protein concentration was determined either by the Lowry or the BCA assay. The specific ATPase activity was tested by the pyruvate kinase/lactate dehydrogenase assay (Schwartz et al. 1971).

\section{FXYD1 Preparation from E. coli}

Human FXYD1 was expressed in E. coli as described elsewhere (Cirri et al. 2011; Lifshitz et al. 2006; Mishra et al. 2011). FXYD1 carried an N-terminal $\mathrm{His}_{6}$ tag. In short, after breaking the cells with a French press, the light membrane fraction was separated and collected by centrifugation. The membranes were resuspended in the presence of protease inhibitors and stored at $80{ }^{\circ} \mathrm{C}$. FXYD1 was purified similarly to the $\alpha_{1} / \mathrm{His}_{10^{-}} \beta_{1}$ complex: the membranes were solubilized with DDM (DDM:protein 2:1 w/w), and the FXYD1 was purified by metal-chelate chromatography with BD-Talon beads in the presence of $40 \mu \mathrm{M}$ EDTA at a concentration of $1 \mathrm{mg} \mathrm{ml}^{-1}$ protein. The protein was eluted as described above, and the His-tag was removed by treatment with AcTEV protease as described (Mishra et al. 2011). Approximately $50 \mu \mathrm{g}$ of purified protein were obtained from $2.5 \mathrm{~g}$ cells.

FXYD1 was phosphorylated in vitro by PKA during the purification from E. coli. After solubilization and binding to the BD-Talon beads, the beads-bound FXYD1 (approximately $100 \mu \mathrm{g}$ ) was incubated for $5 \mathrm{~h}$ at room temperature with 250,000 units of the catalytic subunit of PKA in a buffer containing $50 \mathrm{mM}$ Tris- $\mathrm{HCl}(\mathrm{pH} 7.5)$, $10 \mathrm{mM} \mathrm{MgCl}_{2}$ and $1 \mathrm{mM} \mathrm{ATP} \mathrm{(Lifshitz} \mathrm{et} \mathrm{al.} \mathrm{2006).}$ Thereafter, the beads were washed to remove the PKA, and the phosphorylated FXYD1 was eluted as described for the unphosphorylated FXYD1. The phosphorylation state was checked with specific antibodies against FXYD1 phosphorylated at Ser68 (a gift from Dr. W. Fuller, University of Dundee) (Fuller et al. 2009).

\section{In Vitro Reconstitution of the $\alpha_{1} / \mathrm{His}_{10^{-}} \beta_{1} / \mathrm{FXYD1}$ Complex}

Reconstitution was performed as published recently (Cirri et al. 2011; Mishra et al. 2011). In short, the solubilized $\alpha_{1} /$ His $_{10}-\beta_{1}$ complex was loaded on BD-Talon beads and incubated in a buffer containing $10 \mathrm{mM}$ imidazole, $20 \mathrm{mM}$ tricine ( $\mathrm{pH} 7.4$ ), $100 \mathrm{mM} \mathrm{NaCl}, 0.1 \mathrm{mg} \mathrm{ml}^{-1} \mathrm{C}_{12} \mathrm{E}_{8}$, $0.05 \mathrm{mg} \mathrm{ml}^{-1}$ SOPS, $0.01 \mathrm{mg} \mathrm{ml}^{-1}$ cholesterol and $10 \%$ glycerol with purified FXYD1 at a 10-fold molar excess. After $4 \mathrm{~h}$ at $6{ }^{\circ} \mathrm{C}$, excess FXYD1 was removed by washing and the complex eluted.

\section{Preparation of Proteoliposomes}

In a first set of experiments, proteoliposomes formed by a mixture of DEPC, SBPC and cholesterol in a ratio of 50:49:1 mol mol ${ }^{-1}$ were prepared. SBPC provides a mix of phospholipids with a broad distribution of fatty acid 
chains, creating a lipid environment comparable to a cell membrane. A small amount of cholesterol was introduced due to the stabilizing effect of this lipid on the recombinant $\alpha_{1} /$ His $_{10}-\beta_{1}$ complex (Haviv et al. 2007). Such lipid composition generates proteoliposomes with a low leak conductance and a high enzyme activity. To investigate the effect of anionic phospholipids on the interaction of FXYD1 with the enzyme, in some experiments the zwitterionic DEPC was replaced with 10, 20, 35 and 50 mol\% of the anionic DOPS. Lipid vesicles containing native $\mathrm{Na}, \mathrm{K}-\mathrm{ATPase}$ from rabbit kidney, purified recombinant $\alpha_{1} /$ His $_{10^{-}} \beta_{1}$ or $\alpha_{1} / \mathrm{His}_{10^{-}} \beta_{1} / \mathrm{FXYD1}$ were prepared by a method similar to the one described before for the reconstitution of bacteriorhodopsin (Lambert et al. 1998). Since DDM cannot be efficiently removed by dialysis due to its low critical micelle concentration $\left(0.01 \%\right.$ at $\left.25^{\circ} \mathrm{C}\right)$, proteoliposomes were obtained by adsorption of the detergent onto SM2 Bio-Beads (BioRad, 2050 mesh). In summary, the addition of an excess of SM2 Bio-Beads to a solution containing a mix of DDM-solubilized native Na,K-ATPase or purified recombinant enzyme and lipid/DDM micelles leads to fast adsorption of the detergent by the beads and the formation of active unilamellar proteoliposomes with an average diameter of $110 \mathrm{~nm}$ (Lambert et al. 1998). Typically, half of the protein molecules are reconstituted with the ATP-binding site facing outward.

The desired lipid mixture was dissolved in $2 \%$ DDM in buffer $\mathrm{H}\left(25 \mathrm{mM}\right.$ imidazole, $1 \mathrm{mM}$ EDTA, $5 \mathrm{mM} \mathrm{MgSO}_{4}$, $5 \mathrm{mM} \mathrm{Na}_{2} \mathrm{SO}_{4}, 70 \mathrm{mM} \mathrm{K}_{2} \mathrm{SO}_{4}, \mathrm{pH}$ 7.2) to obtain a lipid concentration of $8 \mathrm{mg} \mathrm{ml}^{-1}$. Sulfate was chosen as the primary anion since it produces a significantly lower leak current than chloride (Apell et al. 1985; Apell and Bersch 1987). To obtain proteoliposomes with native Na,K-ATPase from rabbit kidney, protein-containing membrane fragments prepared according to Jørgensen (1974) were solubilized with DDM at a protein:detergent ratio of 1:2 (w/w).

Purified recombinant enzyme or solubilized native $\mathrm{Na}, \mathrm{K}-\mathrm{ATPa} e$ from rabbit kidney was diluted with buffer $\mathrm{H}$ to get a protein concentration of $0.1 \mathrm{mg} \mathrm{m}^{-1}$ and mixed with the lipid/DDM mixture at a ratio of $1: 1 \mathrm{v} / \mathrm{v}$. The beads ( $1 \mathrm{mg}$ beads/ $2 \mu \mathrm{l}$ lipid/DDM mixture) were added, and the mixture was incubated overnight at $6{ }^{\circ} \mathrm{C}$ under continuous stirring. Eventually, the solution containing the vesicles was separated from the beads using capillary tips and stored at $0{ }^{\circ} \mathrm{C}$. After being kept on ice for a minimum of $3 \mathrm{~h}$, tight vesicles were obtained. Assuming that all the enzyme molecules reconstitute in the lipid membrane, the final protein:lipid ratio was about 1:15,000, equivalent to six to seven ion pumps per vesicle, half of them oriented inside-out. The specific ATPase activity of the native $\mathrm{Na}, \mathrm{K}-\mathrm{ATPa}$ e before and after solubilization of the membrane fragments as well as after reconstitution in lipid vesicles was determined routinely (Schwartz et al. 1971).
In a second set of experiments, proteoliposomes with lipid mixtures approximating the inner leaflet of the bulk of the plasma membrane of human cardiac myocytes were prepared. A composition of $10 \mathrm{~mol} \%$ cholesterol, $34 \mathrm{~mol} \%$ DPPC, $38 \mathrm{~mol} \%$ DOPE and $18 \mathrm{~mol} \%$ DOPS was chosen. Also in these experiments the DOPS content was varied between 0 and $30 \mathrm{~mol} \%$ in exchange for DOPE to investigate the effect of anionic phospholipids on the interaction of FXYD1 with the enzyme. Due to the lower solubility of such lipid mixtures in DDM, a solution of $1 \%$ DDM and $1 \% \mathrm{C}_{12} \mathrm{E}_{8}$ in buffer $\mathrm{H}$ was chosen to solubilize the lipids. To obtain significant fluorescence signals, the protein concentration was doubled compared to the one used in the first set of experiments.

\section{Detection of Na,K-ATPase-Mediated Ion Transport in Proteoliposomes by Oxonol VI}

Na,K-ATPase transports one positive elementary charge across the membrane during each pump cycle. As a consequence, activation of the inside-out-oriented ion pumps by the addition of ATP to the extravesicular electrolyte generates an inside-positive electric potential. The negatively charged fluorescent dye oxonol VI has been introduced previously as an indicator of inside-positive membrane potentials in vesicles, and it has been shown to detect successfully the electrogenic pump activity of $\mathrm{Na}, \mathrm{K}$ ATPase reconstituted in proteoliposomes (Apell and Bersch 1987). Experiments similar to those reported in Apell and Bersch (1987) were performed. In short, $1 \mathrm{ml}$ of buffer containing $25 \mathrm{mM}$ imidazole, $1 \mathrm{mM}$ EDTA, $2.5 \mathrm{mM} \mathrm{MgSO}_{4}$ and various concentrations of $\mathrm{Na}_{2} \mathrm{SO}_{4}(\mathrm{pH}$ 7.2) was thermally equilibrated in a cuvette. Afterward, $25 \mathrm{nM}$ oxonol VI and a volume of proteoliposomes corresponding to $80 \mu \mathrm{g} \mathrm{ml}^{-1}$ lipid were added. When a steady-state fluorescence level was obtained, $2.5 \mathrm{mM}$ $\mathrm{MgATP}$ was added to trigger pump activity. The pump activity is reflected in a fluorescence increase that exponentially approaches a steady-state level at which the pump current is compensated by the leak current due to the membrane conductance. The experiments were carried out in a Perkin Elmer (Rodgau, Germany) LS 50B luminescence spectrometer. The thermostatically controlled cuvette holder was equipped with a magnetic stirrer. The excitation wavelength was set to $580 \mathrm{~nm}$ (slit width $20 \mathrm{~nm}$ ) and the emission wavelength to $660 \mathrm{~nm}$ (slit width $20 \mathrm{~nm}$ ). Measurements were performed at $20^{\circ} \mathrm{C}$ as described previously (Apell et al. 1990; Apell and Bersch 1987). Tris/ $\mathrm{H}_{2} \mathrm{SO}_{4}$ ( $\mathrm{pH}$ 7.0) was added to the buffer in appropriate concentrations to obtain an ionic strength equivalent to that of the intravesicular medium, unless otherwise indicated. To allow a comparison between different experiments, fluorescence changes were normalized with respect to the 
fluorescence level, $F_{0}$, at membrane voltage 0 , before the addition of ATP. The normalized fluorescence increase can be fitted with a single exponential function

$F_{\text {norm }}(t)=\frac{F(t)-F_{0}}{F_{0}} \cdot\left(1-\mathrm{e}^{t / \tau}\right)$

where $F_{\text {norm }}(t)$ is the normalized fluorescence amplitude, $F(t)$ the measured fluorescence and $\tau$ a characteristic time constant that reflects the pump activity. The initial slope of the fluorescence increase after ATP addition, corresponding to the increase in membrane potential, is proportional to the product of pumping rate and the amount of active pump molecules, averaged over all vesicles (Apell and Bersch 1987). As presented in part 1 of the Supplementary Material, the initial slope can be used as a parameter to determine the pump rate. Its dependence on the extravesicular $\mathrm{Na}^{+}$concentration within the same vesicle preparation can be exploited to evaluate the $K_{1 / 2}$ of $\mathrm{Na}^{+}$ions for activation of the ion pump.

\section{Results}

To investigate the influence of the membrane and its lipid composition, Na,K-ATPase was reconstituted in lipid vesicles, and its $\mathrm{Na}^{+}$-binding kinetics was investigated using oxonol VI to monitor the membrane potential as described in "Materials and Methods" section. The method was applied first to Na,K-ATPase from rabbit kidney reconstituted in vesicles to compare the results with the well-known binding kinetics in native membrane fragments and then extended to vesicle preparations with the recombinant $\alpha_{1} / \mathrm{His}_{10}-\beta_{1}$ isoform with and without FXYD1. Proteoliposomes with different amounts of the anionic phospholipid DOPS were prepared to study the effect of the surface charge density on the protein interaction.
Na,K-ATPase from Rabbit Kidney Reconstituted in Proteoliposomes with Various Lipid Compositions

Proteoliposomes with native $\alpha_{1} / \beta_{1} /$ FXYD 2 complexes isolated from rabbit kidneys were formed as described in "Materials and Methods" section with various amounts of DOPS (0 $50 \mathrm{~mol} \%$ ). The enzyme activity, $E_{\mathrm{a}}$, of $\mathrm{Na}, \mathrm{K}-$ ATPase was determined at the different stages of the preparation. While the activity was about $28.5 \mu \mathrm{mol}$ of Pi (mg protein) ${ }^{-1} \mathrm{~min}^{-1}$ in native membrane fragments, it decreased to $2.2 \mu \mathrm{mol}$ of $\mathrm{Pi}$ (mg protein) ${ }^{-1} \mathrm{~min}^{-1}$ after solubilization in DDM. This fact demonstrates that the solubilized environment is less favorable for the enzyme activity, as has been reported recently (Habeck et al. 2009). Indeed, part of the enzyme activity was regained after reconstitution in proteoliposomes, depending on the lipid composition (Table 1). In particular, the specific activity increases linearly with the amount of DOPS in the membrane, up to almost fourfold the activity after solubilization. This observation is not surprising since the need for anionic phospholipids for Na,K-ATPase activity is well documented (Cohen et al. 2005; de Pont et al. 1978; Lifshitz et al. 2007). For the comparison it must be taken into account that, in the vesicles, only $50 \%$ of the protein is inside-out-oriented and has access to and hydrolyzes the added ATP. At $50 \mathrm{~mol} \%$ DOPS, $E_{\mathrm{a}}$ was found to be $30 \%$ of that of the native membrane fragments. Since only half of the enzyme is inside-out-oriented and hydrolyzing ATP, the total amount of active $\mathrm{Na}, \mathrm{K}$-ATPase can be estimated to be about $60 \%$ of the native enzyme. Thus, $40 \%$ of the activity lost by solubilization could not be regained.

The $K_{1 / 2}$ of $\mathrm{Na}^{+}$ions for activation of the native Na,KATPase was investigated in vesicles of different lipid composition by the oxonol VI method as described in "Materials and Methods" section. Figure 1a shows a typical experiment with vesicles prepared with SBPC in a buffer containing $75 \mathrm{mM} \mathrm{Na}^{+}$. When $2.5 \mathrm{mM}$ ATP were

Table 1 Comparison of the effects of DOPS on kinetic parameters of Na,K ATPase from rabbit kidney

\begin{tabular}{llllll}
\hline DOPS & $E_{\mathrm{a}}$ (normalized) $^{\mathrm{a}}$ & \multicolumn{1}{c}{$v_{\max }^{\mathrm{b}}$} & $K_{1 / 2}(\mathrm{mM})^{\mathrm{c}}$ & $n^{\mathrm{c}}$ & $G_{\mathrm{m}}\left(\mathrm{nS} \mathrm{s}^{-1}\right)^{\mathrm{d}}$ \\
\hline $0 \%$ & 1.69 & $707 \pm 8$ & $11.4 \pm 0.2$ & $2.0 \pm 0.1$ & 4.1 \\
$10 \%$ & 1.60 & $815 \pm 17$ & $10.7 \pm 0.4$ & $1.8 \pm 0.1$ & 3.0 \\
$20 \%$ & 2.25 & $843 \pm 21$ & $10.2 \pm 0.4$ & $1.9 \pm 0.1$ & 3.3 \\
$35 \%$ & 3.25 & $1,370 \pm 18$ & $11.3 \pm 0.2$ & $2.1 \pm 0.1$ & 5.0 \\
$50 \%$ & 3.73 & $1,618 \pm 39$ & $13.2 \pm 0.5$ & $1.9 \pm 0.1$ & 10.0 \\
\hline
\end{tabular}

${ }^{\mathrm{a}} E_{\mathrm{a}}$ is given with respect to the enzyme activity of solubilized Na,K ATPase, $2.2 \mu \mathrm{mol}$ of Pi (mg protein) ${ }^{-1} \mathrm{~min}^{-1}$. Values were obtained from two different vesicle preparations each

${ }^{\mathrm{b}} v_{\max }$ is defined as $v_{\max }(\mathrm{d} F / \mathrm{d} t)_{\max } / \mathrm{s}^{-1}$ (see Fig. 1), which is a quantity proportional to the pump current through the vesicle membrane generated by Na,K ATPase

${ }^{\mathrm{c}} K_{1 / 2}$ and $n$ represent the half saturating $\mathrm{Na}^{+}$concentration and the Hill coefficient, respectively, obtained from Eq. 2

d $G_{\mathrm{m}}$ is the leak conductance of the membranes, evaluated as described in "Results" section 

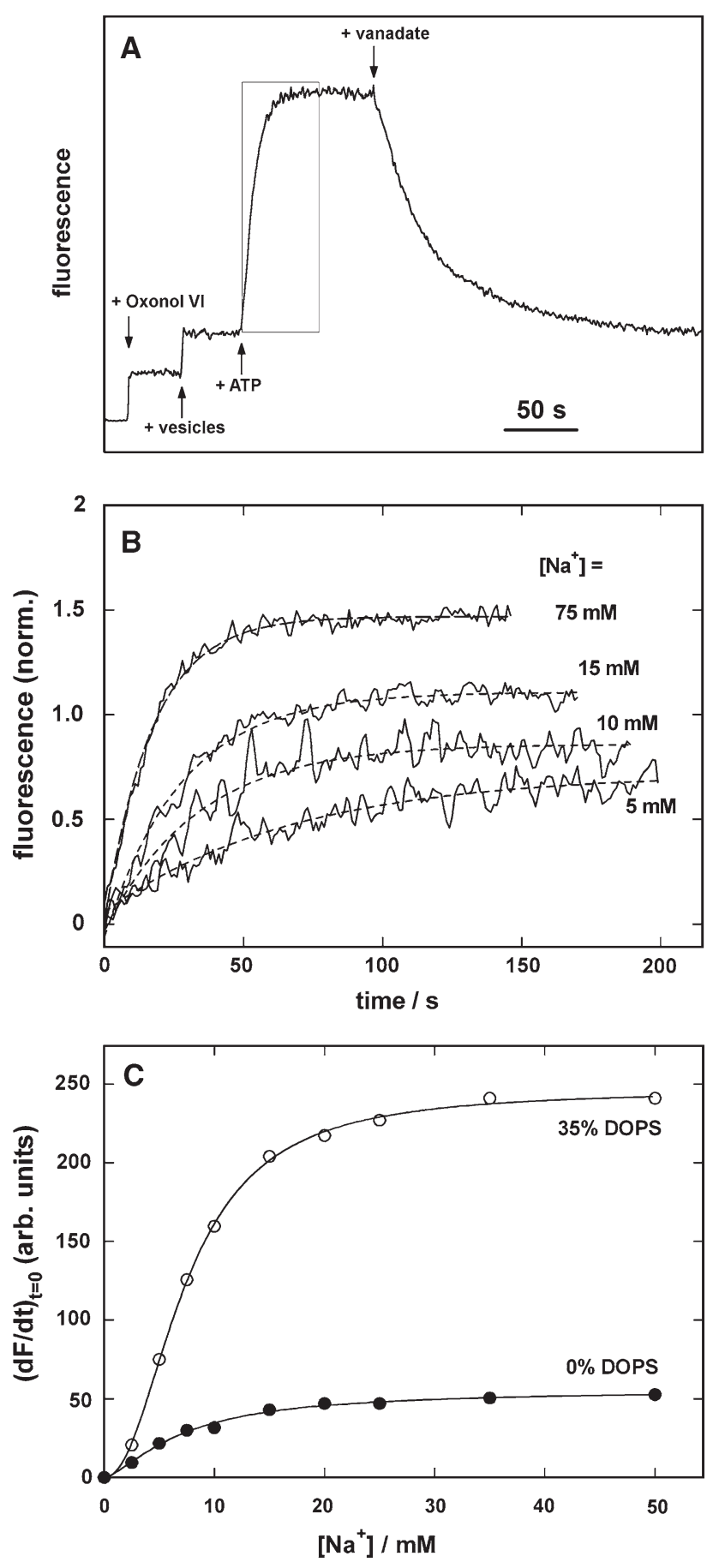

added, the generation of an inside-positive potential was observed, allowing determination of the pump activity of $\mathrm{Na}$,K-ATPase. After reaching a steady state, the ion pump was completely inhibited by addition of $5 \mathrm{mM}$ ortho-vanadate. The observed decrease of the fluorescence signal corresponds to the passive discharge of the membrane capacitor of the vesicles. This exponential decay is controlled by a time constant, $\tau_{\mathrm{m}}=C_{\mathrm{m}} / G_{\mathrm{m}}$, where $C_{\mathrm{m}}$ is the specific membrane capacitance $\left(\sim 1 \mu \mathrm{F} \mathrm{cm}{ }^{-2}\right)$ and $G_{\mathrm{m}}$ is the specific membrane conductance. The latter can be
Fig. 1 Analysis of Na,K ATPase dependent generation of the elec tric membrane potential in proteoliposomes. a Typical oxonol VI experiment. After equilibration of proteoliposomes reconstituted with $\mathrm{Na}, \mathrm{K}$ ATPase from rabbit kidneys in an electrolyte containing oxonol VI, $2.5 \mathrm{mM} \mathrm{MgATP}$ was added to start pump activity, which builds up an inside positive membrane potential. After about $50 \mathrm{~s}$, a steady state was maintained in which the pump current was balanced by the leak current. When $5 \mathrm{mM}$ ortho vanadate was added $\mathrm{Na}, \mathrm{K}$ ATP was inhibited and the membrane potential declined exponentially with a time constant controlled by the leak conductance of the membrane. Box indicates the part of the experiment used to study the $\mathrm{Na}^{+}$ concentration dependence. b ATP induced generation of the mem brane potential at the indicated $\mathrm{Na}^{+}$concentrations in the extrave sicular (=cytoplasmic) electrolyte. The time course was fitted by a single exponential (Eq. 1), shown by the dashed lines. c The initial slope of the fluorescence increase was determined and is plotted as a function of $\mathrm{Na}^{+}$concentration. Two series of experiments were performed, in $50 \%$ DEPC $+49 \%$ SBPC $+1 \%$ cholesterol $(0 \%$ DOPS) and in $15 \%$ DEPC $+49 \%$ SBPC $+35 \%$ DOPS $+1 \%$ cholesterol (35\% DOPS). The concentration dependence was fitted by the Hill function (solid lines)

determined from $G_{\mathrm{m}}=C_{\mathrm{m}} / \tau_{\mathrm{m}}$. The time course of the ATP-induced fluorescence signal (see box in Fig. 1a) has been fitted by Eq. 1. Examples of single experiments at four $\mathrm{Na}^{+}$concentrations are shown in Fig. 1b. Two parameters, $\tau$ and $F_{\infty}$, are obtained from the fits that allow determination of the initial slope, $(\mathrm{d} U / \mathrm{d} t)_{t=0}=K^{*} \times(\mathrm{d} F /$ $\mathrm{d} t)_{t=0}$, a measure of the pump current (see Part 1 in the Electronic Supplementary Material). Within the same vesicle preparation, the proportionality constant, $K^{*}$, which depends on the properties of each specific vesicle preparation, is invariable. Therefore, the initial slopes can be compared directly. Such experiments were performed in buffers with $\mathrm{Na}^{+}$concentrations between 0 and $50 \mathrm{mM}$ and with lipid mixtures between 0 and 50 mol\% DOPS. The $\mathrm{Na}^{+}$concentration dependence in the absence and presence of $35 \mathrm{~mol} \%$ DOPS is shown in Fig. 1c. It was fitted by the Hill function

$$
\left(\frac{\mathrm{d} F\left(\left[\mathrm{Na}^{+}\right]\right)}{\mathrm{d} t}\right)_{t=0}=\left(\frac{\mathrm{d} F}{\mathrm{~d} t}\right)_{\text {max }} \cdot \frac{\left[\mathrm{Na}^{+}\right]^{n}}{K_{1 / 2}^{n}+\left[\mathrm{Na}^{+}\right]^{n}},
$$

where $(\mathrm{d} F / \mathrm{d} t)_{\max }$ is the initial slope at saturating $\mathrm{Na}^{+}$ concentrations, when ion binding is no longer limiting; $K_{1 / 2}$ is the half-saturating $\mathrm{Na}^{+}$concentration; and $n$ is the Hill coefficient, which indicates that cooperative ion binding takes place when $n>1$. The results, obtained as the average of three identical experiments for each $\mathrm{Na}^{+}$concentration and lipid composition from one set of vesicle preparation, are compared in Table 1 . The results show that both the enzyme activity, $E_{\mathrm{a}}$, and the maximum initial slope (or pump flux), $v_{\max }$, increase accordingly with the amount of DOPS in the membranes. $K_{1 / 2}$ was less significantly affected. It decreased slightly between 0 and $20 \mathrm{~mol} \%$ of DOPS and increased about $30 \%$ between 20 and $50 \mathrm{~mol} \%$. The Hill coefficient was hardly affected, with an average of $2.0 \pm 0.1$. When these results are 
compared with $\mathrm{Na}^{+}$binding in native membrane fragments (of undetermined lipid composition), the binding kinetics is similar, with a Hill coefficient of $\sim 2$. The enzyme activity is, however, a factor of 1.7 times larger in native membranes (see above), while $K_{1 / 2}$ is $4.2 \pm 0.3 \mathrm{mM}$. This difference may be assigned to a variant lipid composition in the native membranes. In summary, it can be stated that this experimental approach is suitable to determine the $\mathrm{Na}^{+}$-binding kinetics of $\mathrm{Na}, \mathrm{K}$-ATPase in various lipid environments.

Recombinant Na,K-ATPase Complexes $\alpha_{1} / \mathrm{His}_{10}-\beta_{1}$ and $\alpha_{1} /$ His $_{10}-\beta_{1} /$ FXYD1 Reconstituted

in Proteoliposomes with Various Lipid Compositions

Proteoliposomes containing the $\alpha_{1} / \mathrm{His}_{10^{-}} \beta_{1}$ or $\alpha_{1} / \mathrm{His}_{10^{-}} \beta_{1} /$ FXYD1 enzyme in lipid mixtures of SBPC, DEPC, cholesterol and DOPS were prepared as described in "Materials and Methods" section. Again, the $\mathrm{Na}^{+}$concentrationdependent pump activity was derived from the oxonol VI fluorescence signals, as shown in Fig. 1. The kinetic parameters at different amounts of DOPS in the lipid mixtures of the vesicle membranes were determined from the experiments in different $\mathrm{NaSO}_{4}$ buffer. Values were obtained from the average of three sets of experiments at various $\mathrm{Na}^{+}$concentrations for each vesicle preparation. For lipid compositions containing 0, 20 and $50 \mathrm{~mol} \%$ DOPS, the results were averaged with those obtained with a second vesicle preparation. (Note that all purified preparations contained added SOPS. Thus, in the vesicle experiments, the observed effects of added DOPS are over and above those of SOPS in the enzyme preparations.)

Comparison of the $K_{1 / 2}$ values for both preparations in Fig. 2a shows that the presence of FXYD1 (solid line) raised the $K_{1 / 2}$ of $\mathrm{Na}^{+}$ions for activation of the human $\alpha_{1}$ / His $_{10}-\beta_{1}$ complex. This finding is in agreement with respective findings obtained from studies in whole cells and supports the suggestion that the presence of a lipid bilayer plays a role in the functional properties of FXYD1. This is supported by the observation that also the amount of DOPS in the lipid bilayer affected the $K_{1 / 2}$ of $\mathrm{Na}^{+}$ions. Between 0 and $20 \mathrm{~mol} \%$ DOPS the value of $K_{1 / 2}$ decreased by about $25 \%$ in the presence of FXYD1. The slight increase at $50 \mathrm{~mol} \%$ DOPS should be viewed with caution since in this condition the leak conductance of the vesicle membrane and the maximal pump rate (at saturating $\mathrm{Na}^{+}$ concentration) are also affected (Fig. 2). By comparison, $K_{1 / 2}$ exhibited no significant dependence on DOPS concentration in the absence of FXYD1, with a value of $14 \pm 0.6 \mathrm{mM}$ within the whole range. Above $20 \mathrm{~mol} \%$ DOPS no significant difference of $K_{1 / 2}$ was visible for both preparations. The cooperativity of $\mathrm{Na}^{+}$activation as reflected in the Hill coefficient, $n_{\mathrm{H}}$, was affected neither by the presence of FXYD1 nor by the DOPS contents of the lipid bilayer (Fig. 2b). The third parameter obtained from the vesicle experiments is the maximum pump rate, which is proportional to the initial fluorescence increase, $\mathrm{d} F /\left.\mathrm{d} t\right|_{t=0}$, obtained at saturating $\mathrm{Na}^{+}$concentrations (Fig. 2c). This pump rate, $v$, is proportional to the number of active pumps, $N_{\mathrm{P}}$, and the individual turnover rate of $\mathrm{Na}, \mathrm{K}$ ATPase, $v_{\mathrm{P}}$,

$\mathrm{d} F /\left.\mathrm{d} t\right|_{t=0} \sim v=N_{\mathrm{P}} \times v_{\mathrm{P}}$.

In the presence of FXYD1 the pump rate was largely independent of DOPS and about $50 \%$ higher than that in the preparation without FXYD1. This finding reflects the welldocumented stabilization effect of FXYD1 and indicates a higher number of active pump molecules (Mishra et al. 2011). In the absence of FXYD1 the stabilizing effect of DOPS is obvious by the increase of the pump rate by a factor of 3 between 0 and $35 \mathrm{~mol} \%$ DOPS. The last parameter evaluated from the vesicle experiments was the leak conductance of the membranes. It was found that $G_{\mathrm{m}}$ was constant for both preparations up to a content of $35 \mathrm{~mol} \%$ DOPS $\left(2.7 \pm 0.4 \mathrm{nS} \mathrm{cm}^{-2}\right)$. At $50 \mathrm{~mol} \%$ an increased leak conductance was found in both preparations (Fig. 2d).

\section{Effect of Ionic Strength}

The vesicle preparations used so far were studied in an electrolyte with an ionic strength of $\sim 250 \mathrm{mM}$, but the ionic strength of the cytosol in heart muscle cells is on the order of $100 \mathrm{mM}$. Therefore, we tested whether an appropriately reduced ionic strength would affect the $\mathrm{Na}^{+}$binding properties and the regulatory properties of FXYD1. These controls are important in so far as it is known that the electric surface potential of membranes is controlled by the ionic strength according to the Gouy-Chapman theory (McLaughlin 1977). Since the modulatory action of FXYD1 depends on the ratio of the negatively charged DOPS in the membrane (Fig. 2a), the electrostatic interaction between the basic amino acids at the mobile C-terminal domain of FXYD1 and the negative membrane surface has to be considered. When the ionic strength is reduced from 250 to $110 \mathrm{mM}$, the Debye length of electric surface potentials in the solution increases from 0.6 to $0.9 \mathrm{~nm}$, and for a given surface charge the absolute value of the surface potential is increased by about $30 \%$.

To maintain an ionic strength of $\sim 110 \mathrm{mM}$, Tris $/ \mathrm{H}_{2} \mathrm{SO}_{4}$ was added to the extravesicular electrolyte in appropriate amounts. To perform experiments in which the $\mathrm{Na}^{+}$dependent pump current is determined (Fig. 1a), it is necessary that the intravesicular $\mathrm{K}^{+}$concentration is as high as possible in order to maintain the pumps in the $\mathrm{Na}^{+} / \mathrm{K}^{+}$ exchange mode for a sufficiently long period before depletion of $\mathrm{K}^{+}$inside the vesicles and a switch to the 


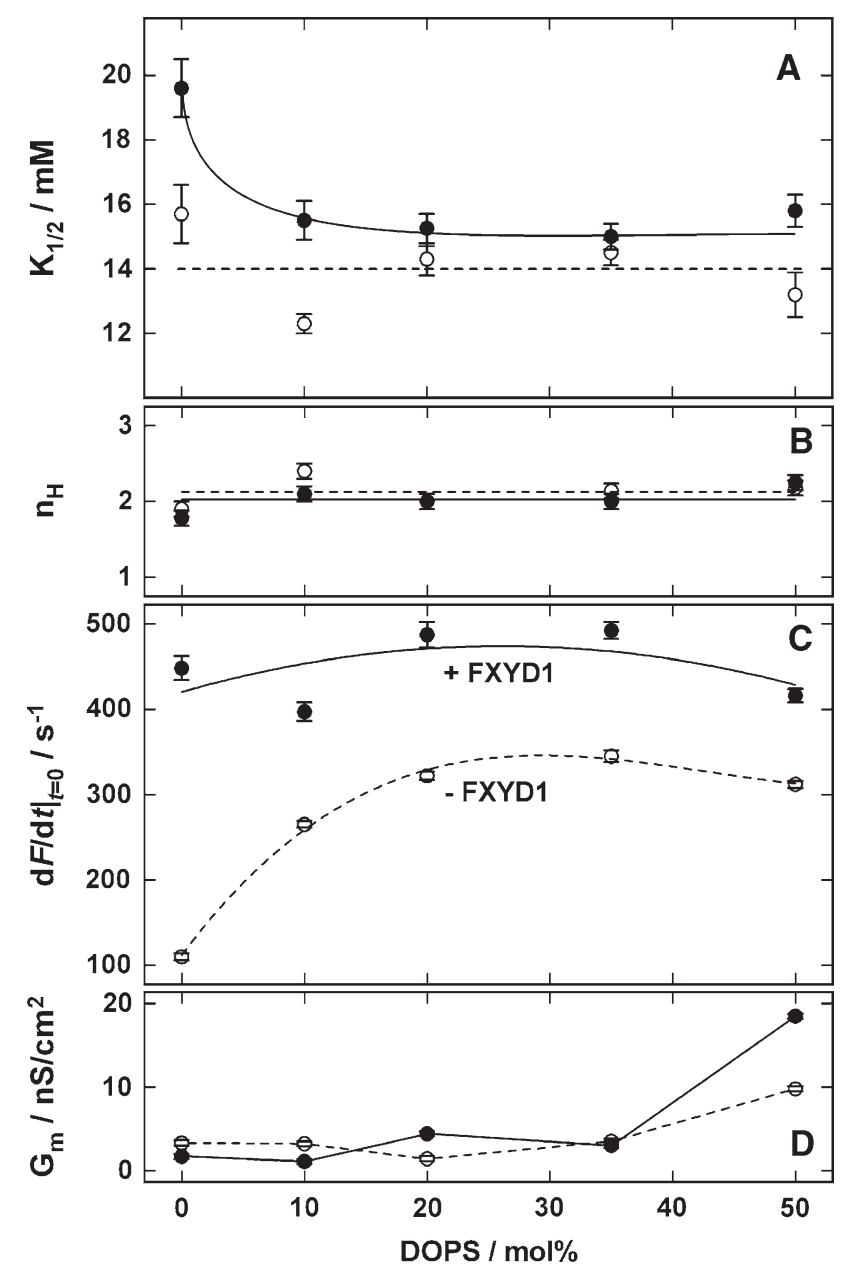

Fig. 2 Effect of the negatively charged lipid DOPS in the vesicle membrane on the $\mathrm{Na}^{+}$binding kinetic of recombinant $\mathrm{Na}, \mathrm{K}$ ATPase. a Comparison of the apparent $\mathrm{Na}^{+}$binding affinity between $\alpha_{1} / \mathrm{His}_{10}$ $\beta_{1}$ (open circles) and $\alpha_{1} / \mathrm{His}_{10} \beta_{1} / \mathrm{FXYD} 1$ (solid circles). The half saturating $\mathrm{Na}^{+}$concentration, $K_{1 / 2}$, is plotted for both preparations as a function of the fraction of DOPS in the membranes. $\mathbf{b}$ The Hill coefficient of the $\mathrm{Na}^{+}$binding kinetics (Eq. 2) was unaffected by the presence or absence of FXYD1 in the Na,K ATPase complex and the DOPS concentration. $\mathbf{c}$ The maximum pump rate of $\alpha_{1} / \mathrm{His}_{10} \beta_{1}$ and $\alpha_{1} / \mathrm{His}_{10} \beta_{1} / \mathrm{FXYD} 1$ represented by the initial slope of the oxonol VI fluorescence after addition of ATP (Fig. 1a) increased as a function of the fraction of DOPS in the membranes. The results indicate clearly the stabilizing effect of FXYD1 and the presence of DOPS. Error bars in all panels represent the SEM. d Leak conductance of the vesicle membranes. Up to 35 mol\% DOPS no significant differences could be observed. At $50 \mathrm{~mol} \%$ DOPS the leak conductance was increased in both preparations

$\mathrm{Na}^{+}$-only pumping mode. Therefore, the ionic strength of the intravesicular solution could not be reduced since that would have produced a significantly lower internal potassium concentration. The experiments were performed at 0 , 20 and $50 \mathrm{~mol} \%$ DOPS (Fig. 3). In the absence of additional DOPS the $K_{1 / 2}$ values were in both preparations $25 \%$ lower when compared to the results at high ionic strength. This decrease of $K_{1 / 2}$ of $\mathrm{Na}^{+}$ions for activation of

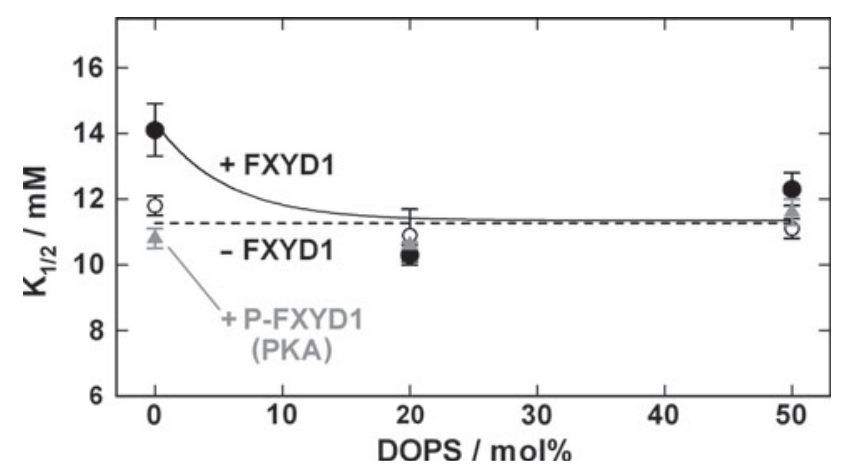

Fig. 3 Comparison of the apparent $\mathrm{Na}^{+}$binding affinity between $\alpha_{1} /$ His $_{10} \beta_{1}$ (open circles) and $\alpha_{1} / \mathrm{His}_{10} \beta_{1} /$ FXYD1 (solid circles) at low ionic strength. The results of the experiments in which FXYD1 was phosphorylated by PKA are included as gray triangles. The half saturating $\mathrm{Na}^{+}$concentration, $K_{1 / 2}$, is plotted for all three types of preparation as a function of the fraction of DOPS in the membranes. Lines are drawn to guide the eye

the pump represents the effect of the increased surface potential of the protein surface close to the entrance of the access channel to the ion-binding sites. When the effect of 20 and $50 \mathrm{~mol} \%$ DOPS on $K_{1 / 2}$ was compared for both vesicle preparations, with $\alpha_{1} / \mathrm{His}_{10^{-}} \beta_{1}$ and $\alpha_{1} / \mathrm{His}_{10^{-}} \beta_{1} /$ FXYD1 enzymes, the differences in the $K_{1 / 2}$ values were not significant, similar to what was found at high ionic strength (Fig. 2a).

On the one hand, the $K_{1 / 2}$ values were unaffected by the amount of DOPS in the vesicle preparations without FXYD1 (Fig. 3). Considering the Debye length, which was less than $1 \mathrm{~nm}$ even at the lower ionic strength, this finding is not surprising since the surface-charge effect on the $\mathrm{Na}^{+}$ concentrations vanishes $\left(\Delta c_{\mathrm{Na}}<4 \%\right)$ within two times the Debye length. This finding indicates that the presence of additional negatively charged DOPS molecules in the membrane does not modify significantly the local $\mathrm{Na}^{+}$ concentration at the entrance of the access channel (for details see Part 2 in the Electronic Supplementary Material). On the other hand, the $K_{1 / 2}$ values were affected by the presence of DOPS when the protein complex contains the FXYD1 subunit. When the DOPS content was increased from 0 to $20 \mathrm{~mol} \%$, the $K_{1 / 2}$ values decreased by more than $20 \%$ in the $\alpha_{1} / \mathrm{His}_{10}-\beta_{1} / \mathrm{FXYD1}$ enzyme, independently of the ionic strength. This observation supports strongly the concept that in the presence of FXYD1 and at elevated DOPS concentrations the decrease of $K_{1 / 2}$ of $\mathrm{Na}$ ions for activation of the pump is attributable to an interaction between the cytoplasmic domain of FXYD1 and the membrane surface. The values of the other kinetic parameters, namely, the Hill coefficient, maximum pump rate and leak conductance, with the different DOPS contents were comparable to those obtained in experiments at high ionic strength (data not shown). 


\section{Effect of Lipid Composition}

Since it has been shown that the DOPS content affected the apparent $K_{1 / 2}$ of $\mathrm{Na}^{+}$ions for activation of the pump, it was logical to look for additional effects of the lipid composition. The critical role of FXYD1 in the heart contraction relaxation mechanism is of particular interest. In order to obtain data most relevant to physiologically relevant conditions, we looked at possible effects of a lipid environment resembling the bulk of the plasma membrane of human cardiac myocytes. Preparations of liposomes with an asymmetric lipid distribution are so far impossible. Since the most interesting kinetic property in our study was the $K_{1 / 2}$ for $\mathrm{Na}^{+}$ions when the ion binding sites are facing the cytoplasm, the lipid composition was chosen to resemble that of the inner layer. In addition, the crucial C-terminal domain of FXYD1 is located on this side. Therefore, a lipid mixture containing $10 \mathrm{~mol} \%$ cholesterol, $34 \mathrm{~mol} \%$ DPPC, $38 \mathrm{~mol} \%$ DOPE and $18 \mathrm{~mol} \%$ DOPS was chosen. This may be considered a reasonable approximation of the cytoplasmic leaflet of the plasma membrane of human cardiac myocytes, which contains about $18 \mathrm{~mol} \%$ of negatively charged phospholipids (Gloster and Harris 1969; Post et al. 1988).

The DOPS dependence of $K_{1 / 2}$ is shown as the most important result in Fig. 4. When the $K_{1 / 2}$ of Na,K-ATPase in the absence FXYD1 is compared with the data obtained from vesicles formed with mixtures of SBPC, DEPC, cholesterol and DOPS only (Fig. 2a), the $\mathrm{Na}^{+}$affinity was increased by almost a factor of 2 in the lipid environment simulating a cardiac cell. This observation indicates that the $K_{1 / 2}$ of $\mathrm{Na}^{+}$ions can be significantly affected by the lipid environment, even in the absence of FXYD1. The overall tendency of the DOPS concentration on the effect of FXYD1 was the same as found in Fig. 2a. In the absence of DOPS, $K_{1 / 2}$ was $18.1 \pm 1.7 \mathrm{mM}$, which is approximately the same as in the case of the vesicles prepared with SBPC. $K_{1 / 2}$ decreased with increasing DOPS content and had a low constant value of about $8 \pm 0.6 \mathrm{mM}$ above $10 \mathrm{~mol} \%$ DOPS. It seems that the effect of FXYD1 is maximal in the absence of added DOPS and disappears above $10 \%$ DOPS.

\section{Effect of FXYD1 Phosphorylation by PKA}

To test the effect of FXYD1 phosphorylation on the $\mathrm{Na}^{+}$binding affinity, the PKA-phosphorylated FXYD1 was reconstituted with $\alpha_{1} / \mathrm{His}_{10^{-}} \beta_{1}$ and used to produce proteoliposomes with the lipid compositions introduced above containing DOPS up to $50 \mathrm{~mol} \%$. In a first set of experiments, an ionic strength of $110 \mathrm{mM}$ was chosen for the extravesicular electrolyte, and $K_{1 / 2}$ was determined at 0,20 and $50 \mathrm{~mol} \%$ DOPS. The results are included as triangles

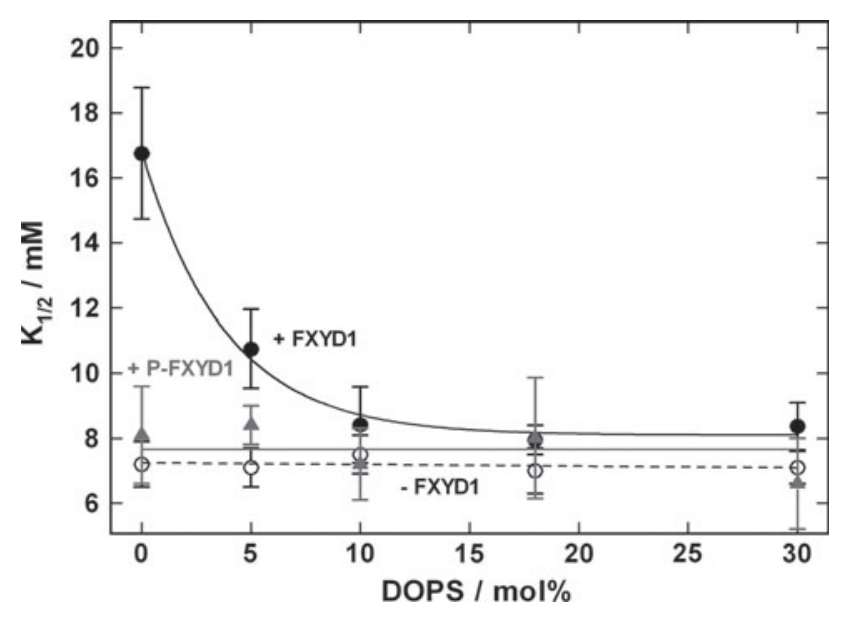

Fig. 4 Comparison of the apparent $\mathrm{Na}^{+}$binding affinity between $\alpha_{1}$ / His $_{10} \beta_{1}$ (open circles) and $\alpha_{1} /$ His $_{10} \beta_{1} /$ FXYD1 (solid circles) in a lipid mixture containing $10 \mathrm{~mol} \%$ cholesterol, $34 \mathrm{~mol} \%$ DPPC and $56 \mathrm{~mol} \%$ (DOPS + DOPE). The results obtained with phosphory lated FXYD1 are included as gray triangles. $K_{1 / 2}$ is plotted for both preparations as a function of the fraction of DOPS in the membranes. Line through the +FXYD1 data is drawn to guide the eye; both straight lines represent the average of the data

in Fig. 3. The $K_{1 / 2}$ of $\mathrm{Na}^{+}$ions was only insignificantly dependent on the DOPS concentration, similar to the results obtained in the absence of FXYD1. This outcome indicates that no interaction occurs between the in vitro PKA-phosphorylated FXYD1 and the cytoplasmic domain of the pump that affects the $\mathrm{Na}^{+}$-binding kinetics. In a second set of experiments, the lipid composition was set to $10 \mathrm{~mol} \%$ cholesterol, $34 \mathrm{~mol} \%$ DPPC and various amounts of DOPE and DOPS (together $56 \mathrm{~mol} \%$ ) to allow a comparison with the results obtained in the presence of unphosphorylated FXYD1 in vesicles with a lipid composition mimicking cardiac myocyte membranes (Fig 4). Phosphorylation of FXYD1 reversed the effect on the $K_{1 / 2}$ of $\mathrm{Na}^{+}$ions also in such a lipid environment: up to $30 \mathrm{~mol} \%$ DOPS, the average $K_{1 / 2}$ was $7.7 \pm 0.3 \mathrm{mM}$, not significantly different from the value obtained in the absence of FXYD1 (7.2 $\pm 0.6 \mathrm{mM})$. Therefore, phosphorylation of Ser68 by PKA is able to abolish the effect of FXYD1 on the $K_{1 / 2}$ of $\mathrm{Na}^{+}$ions also in the case of a lipid composition close to that of cardiac myocytes.

\section{Discussion}

Previously, the effects of FXYD1 on Na,K-ATPase were investigated largely in intact cells, both heterologous systems and native cells. These systems easily allow characterization of the effects of FXYD1 in conditions resembling the physiological setting. They are, however, only of limited use for detailed studies of functional and 
structural interactions between FXYD1 and Na,K-ATPase. In contrast, purified, detergent-solubilized recombinant preparations provide a system that enables us to work under well-defined conditions and without interference from other cellular components. Unlike the conditions in native cells, reconstitution of $\alpha \beta F X Y D 1$ complexes in vitro allows the FXYD1: $\alpha \beta$ stoichiometry to be varied experimentally, and effects of FXYD1 on the different isoforms of Na,K-ATPase can be investigated separately. Moreover, since the phosphorylation state of FXYD1 in the purified preparations is easily controllable, the functional properties of the protein kinase-mediated phosphorylation of FXYD1 can be investigated.

Recently, the electrochromic styryl dye RH421 was applied in steady-state and time-resolved kinetic measurements to characterize the effects of FXYD1 on the different partial reactions of the transport cycle of the human $\alpha_{1} / \beta_{1}$ isoform of $\mathrm{Na}, \mathrm{K}-\mathrm{ATPase}$ in isolated, solubilized, reconstituted $\alpha_{1} \beta_{1}$ FXYD1 complexes. In these experiments only a single kinetic property of FXYD1 was affected, namely, the $\mathrm{Na}^{+}$-binding affinity. In both conformations, $\mathrm{E}_{1}$ and $\mathrm{P}-\mathrm{E}_{2}$, the apparent $\mathrm{Na}^{+}$-binding affinity was increased by $\sim 2030 \%$ (Cirri et al. 2011). This observation was striking because it appears to be contrary to the findings of experiments in whole cells, in which it has been found that the presence of FXYD1 leads to a raised $K_{1 / 2}$ of $\mathrm{Na}^{+}$ions for activation of the pump. A major difference between the two systems is the absence of a lipid bilayer surrounding Na,K-ATPase in the case of isolated complexes. They have only specifically bound SOPS and cholesterol molecules and remaining annular lipids, as well as detergent molecules in a protein lipid detergent mixed micelle. This state may affect the functional role of the highly mobile C-terminal domain of FXYD1. Therefore, the $\mathrm{Na}^{+}$binding kinetics was revisited in a system that still contained Na,K-ATPase with or without FXYD1 as the only protein but provided an extended lipid-bilayer environment. For this purpose, in the present study, the recombinant enzyme was reconstituted in unilamellar vesicles.

Upon reconstitution in lipid vesicles with up to $10 \mathrm{~mol} \%$ added DOPS, FXYD1 induced a significant increase in the $K_{1 / 2}$ of $\mathrm{Na}^{+}$ions for activation of the pump (Figs. 2a, 3, 4), similar to what has been detected in intact cells in the presence of unphosphorylated FXYD1 (Bibert et al. 2008; Bossuyt et al. 2009; Crambert et al. 2002b; Despa et al. 2005; Han et al. 2009, 2010; Lifshitz et al. 2006). These results demonstrate, first, that FXYD1 associates correctly with the enzyme during in vitro reconstitution since the behavior resembles that found in native cell membranes. The second finding is that the presence of a lipid bilayer affects significantly the functional mechanism of FXYD1. And the third insight is that a variation of the surfacecharge density of the lipid bilayer may be used to modulate the interaction of FXYD1 with Na,K-ATPase.
Functional Differences Between the $\alpha_{1} / \mathrm{His}_{10^{-}} \beta_{1} /$ FXYD1 Enzyme in Complexes and Membranes

Two domains of the FXYD1 molecule appear to underlie its regulatory effects: the membrane domain (H2) and the C-terminal domain (including $\mathrm{H} 4$ ). In the isolated complexes as well as in the membrane-reconstituted form, the membrane domains of FXYD1, $\mathrm{H} 2$ and $\mathrm{H} 9$ of the $\alpha_{1}$-subunit, should be in functional contact since the stabilizing effect of FXYD1 on Na,K-ATPase has been found in both detergent-soluble, isolated complexes and native cell membranes (Mishra et al. 2011). In addition, reconstitution of FXYD1 with $\alpha_{1} / \mathrm{His}_{10}-\beta_{1}$ is performed identically before complex isolation and vesicle formation. The addition of (functional) lipids during complex formation is assumed to form a stable protein complex with a few specifically bound lipid molecules (SOPS, cholesterol) that create the active complex (Haviv et al. 2007). The additional lipid and residual detergent molecules are assumed to constitute an annulus with a hydrophobic core that mimics a lipid bilayer and thus hides the hydrophobic surface of $\mathrm{Na}, \mathrm{K}$ ATPase from the aqueous phase. Therefore, it may be anticipated that the interaction of the membrane domains is comparable in isolated complexes and membranes.

Considering the interaction between the cytoplasmic domains of FXYD1 and the pump, major differences may be expected. In the isolated complexes, the lipid annulus surrounding the pump contains mostly negatively charged SOPS, added during the purification to preserve enzyme activity. In this condition, the cytoplasmic domain of FXYD1 could be bent away from the N, P and A domains of the pump and interact irreversibly with the curved surface of the annulus. The NMR structure of FXYD1 in SDS micelles shows such a structure (Teriete et al. 2007). In that study, the observation that the cytoplasmic part of FXYD1 reveals only minor variations in its localization indicates that the C-terminal end is preferentially localized on the surface of the negatively charged SDS micelle. If such a conformation is established and the C-terminal FXYD1 domain is completely separated from the cytoplasmic domain of $\mathrm{Na}, \mathrm{K}$-ATPase, the difference in $\mathrm{Na}$ affinity in the presence and absence of FXYD1 observed in Cirri et al. (2011) would be attributable to an interaction of the membrane domains. In this situation the interaction of the membrane domain of FXYD1 with the pump would support the formation of a conformation of the membrane domain of the $\alpha_{1}$-subunit that enhances $\mathrm{Na}^{+}$binding.

When the $\alpha_{1} / \mathrm{His}_{10}-\beta_{1} /$ FXYD1 enzyme is reconstituted in vesicles of mostly uncharged lipids, the mobile C-terminal domain of FXYD1 may be no longer adsorbed to the surface and may be able to interact frequently with the cytoplasmic N, P and A domains of Na,K-ATPase. Possible kinetic mechanisms of the observed effects of FXYD1 
assume that the cytoplasmic interaction either forces the pump's membrane domain to switch from a more to a less favorable conformation of the $\mathrm{Na}^{+}$-binding sites or, alternatively, that it affects the $E_{1} E_{2}$ conformational equilibria. A functional coupling of conformational rearrangements between the ion-binding sites in the membrane domain and the cytoplasmic nucleotide-binding domain has been demonstrated already in an earlier study. It has been shown that binding of the third $\mathrm{Na}^{+}$is coupled with a conformational rearrangement at the ATP-binding site (Schneeberger and Apell 1999). In consequence, the more frequently the cytoplasmic domain of FXYD1 contacts $\mathrm{Na}, \mathrm{K}-\mathrm{ATPa}$ e and affects its conformational movements, the more often the ion-binding sites are forced to stay in a less favorable conformation for binding of the third $\mathrm{Na}^{+}$ ion and the lower is the apparent $\mathrm{Na}^{+}$-binding affinity.

In relation to $\mathrm{E}_{1} \mathrm{E}_{2}$ conformational equilibria, it should be noted that the $K_{1 / 2}$ of $\mathrm{Na}^{+}$ions for activation of the steady-state Na,K-pump current in proteoliposomes, measured with oxonol VI, and the $\mathrm{Na}^{+}$affinity of soluble $\alpha \beta$ complexes, measured with RH421, are not identical kinetic parameters. In particular the $K_{1 / 2}$ of $\mathrm{Na}^{+}$ions reflects both cytoplasmic $\mathrm{Na}^{+}$affinities and rate constants of the various transitions around the enzymatic cycle. In a subsequent article we shall present data showing that in defined conditions FXYD1 reduces the maximal turnover rate of soluble $\alpha_{1} \beta_{1}$ complexes (Mishra et al., unpublished data), demonstrating that it can affect rate-limiting steps of the enzymatic cycle as well as $\mathrm{Na}^{+}$-binding affinities already described (Cirri et al. 2011). Phosphorylation of FXYD1 at Ser68 would release the C-terminal helix from the $\alpha$-subunit and reverse these effects. Further experimental tests are necessary to determine the exact kinetic mechanism.

\section{The Modulatory Role of the Negative Charges} on the Bilayer

The DOPS concentration dependence of $K_{1 / 2}$ presented in Figs. 2a, 3 and 4 can be explained by electrostatic interactions between the negatively charged DOPS head groups and the positive charges in the cytoplasmic domain of FXYD1. Four basic amino acids are located close to the cytoplasm membrane interface (Arg 38, 39, 41 and Lys 43) and seven in $\mathrm{H} 4$, the preceding loop and the $\mathrm{C}$ terminus (Arg 49, 61, 65, 66, 70, 71 and 72). At concentrations of DOPS $>15 \mathrm{~mol} \%, K_{1 / 2}$ was not affected by the regulatory subunit and exhibited values similar to that of $\mathrm{Na}, \mathrm{K}$ ATPase without FXYD1 (Figs. 2, 3, 4). At such high concentrations of DOPS, the electrostatic attraction by the lipid surface may become so strong that the mobile $\mathrm{C}$ terminus of FXYD1 remains most of the time trapped there after having contacted the membrane surface during its diffusional movements. At a low DOPS concentration
$(<10 \mathrm{~mol} \%)$ the $K_{1 / 2}$ value was significantly larger in $\alpha_{1} /$ His $_{10}-\beta_{1} /$ FXYD1 than in $\alpha_{1} /$ His $_{10^{-}} \beta_{1}$. This experimental finding is in agreement with the concept that at a lower negative charge of the membrane surface FXYD1 interacts more strongly with the $\alpha$-subunit.

Several studies have approved that unphosphorylated FXYD1 reduces the apparent affinity of the Na,K-ATPase for intracellular $\mathrm{Na}^{+}$ions in both cardiac myocytes (Bossuyt et al. 2009; Despa et al. 2005; Han et al. 2009) and heterologous expression systems (Bibert et al. 2008; Crambert et al. 2002a; Han et al. 2010; Lifshitz et al. 2006). In the bulk of the plasma membrane of human cardiac myocytes the total content of negatively charged lipid head groups has been estimated to be on the order of $18 \mathrm{~mol} \%$ with a fraction of $\sim 3 \mathrm{~mol} \%$ phosphatidylserine (Gloster and Harris 1969). In vesicle preparations with correspondingly high amounts of DOPS, we observed no difference in $\mathrm{Na}^{+}$-binding affinity, which apparently contradicts the results obtained in intact cells. Recent investigations, however, have reported that a significant fraction of the Na,K-ATPase in rat cardiac myocytes is localized in caveolae (Liu et al. 2003; Liu and Askari 2006). The precise lipid composition of caveolae is not known and is likely to vary among distinct cell types (Smart et al. 1999). Nevertheless, they are enriched in cholesterol and sphingolipids that form a liquid-ordered lipid phase (Anderson 1998; Smart et al. 1999) and contain an amount of negatively charged phospholipids significantly smaller compared to the bulk of the plasma membrane, probably $<5 \%$ (Brown and Rose 1992). Taking this into account, our findings can be considered to be in accordance with observations in cardiac myocytes.

\section{FXYD1 Phosphorylation}

The increase of the negative charge of the membrane surface is shown to affect the interaction between unphosphorylated FXYD1 and the cytoplasmic domain of $\mathrm{Na}, \mathrm{K}-$ ATPase. However, this is not a physiologically relevant mechanism to regulate the ion-pump activity under changing physiological requirements since it would require a massive increase of the DOPS (or, more generally, anionic phospholipid) content of the cytoplasmic lipid monolayer (above $15 \mathrm{~mol} \%$ ) to dispose the effect on $K_{1 / 2}$ of $\mathrm{Na}^{+}$binding. As recently published, the actual regulatory effect in cardiac myocytes is caused by phosphorylation of FXYD1 (Bibert et al. 2008; Bossuyt et al. 2009; Despa et al. 2005; Fuller et al. 2004, 2009; Pavlovic et al. 2007; Silverman et al. 2005). This concept is supported by the phosphorylation experiments shown in Figs. 3 and 4. Phosphorylation of FXYD1 by PKA reduces the observed increase of $K_{1 / 2}$ of the $\alpha_{1} / \mathrm{His}_{10}-\beta_{1} / \mathrm{FXYD} 1$ complex in the physiologically relevant range of DOPS concentrations in 
the membrane. This effect was independent of the amount of negatively charged lipids and may be assigned to a defective interaction of the C-terminal end of FXYD1 with the cytoplasmic domain of the Na,K-ATPase.

\section{Structural and Mechanistic Implications}

A molecular-dynamic simulation shows attachments between FXYD1 and the N domain of the $\alpha$-subunit stabilized by electrostatic interactions and hydrogen bonds (see Part 3 in the Electronic Supplementary Material). This provides a possible concept to explain the regulation of the $\mathrm{Na}^{+}$binding affinity of Na,K-ATPase by FXYD1, based on the interaction of the C-terminal part of FXYD1 with the nucleotide-binding domain of the $\alpha$-subunit of Na,K-ATPase. Under physiological conditions, the highly mobile terminus of FXYD1, which includes the arginine-rich helix H4, may be able to interact with negatively charge glutamates on the surface of the $\mathrm{N}$ domain. As explained above, an interaction with FXYD1 could be translated to the membrane domain and reduce the intrinsic affinity for the third $\mathrm{Na}^{+}$binding site. Alternatively, since the available crystal structure used for these simulation is an $\mathrm{E}_{2}$ conformation, the predicted interaction could reduce the interconversion of the $\mathrm{N}$ domain between spatial arrangements in the $\mathrm{E}_{1}$ and $\mathrm{E}_{2}$ conformations, stabilize the $\mathrm{E}_{2}$ conformation and, thus, reduce the fraction of enzyme in the $\mathrm{E}_{1}$ conformation able to bind $\mathrm{Na}^{+}$in the steady state. Either modification of the intrinsic $\mathrm{Na}^{+}$-binding affinity to the third $\mathrm{Na}^{+}$site or the shift in the conformation equilibrium toward $E_{2}$ would be reflected also as a decreased apparent $\mathrm{Na}^{+}$-binding affinity in turnover conditions, as detected in the current experiments. Upon phosphorylation of Ser68 in helix H4, interaction with the $\mathrm{N}$ domain may be disrupted and the effect abrogated. Further work is required to distinguish between the possible mechanisms. The structural concept proposed here could, of course, be used as a basis for mutational studies to clarify the role of the involved amino acids in the interaction between FXYD1 and Na,K-ATPase.

Acknowledgments We thank Dr. Kay Diederichs for his help in creating the figures with the molecular structures. The work was financially supported by the German Israeli Foundation (Grant 922165.9 to H. J. A. and S. J. K.)

\section{References}

Anderson RG (1998) The caveolae membrane system. Annu Rev Biochem 67:199 225

Apell H J, Bersch B (1987) Oxonol VI as an optical indicator for membrane potentials in lipid vesicles. Biochim Biophys Acta 903:480 494

Apell H J, Marcus MM, Anner BM, Oetliker H, Läuger P (1985) Optical study of active ion transport in lipid vesicles containing reconstituted Na,K ATPase. J Membr Biol 85:49 63
Apell H J, Häring V, Roudna M (1990) Na,K ATPase in artificial lipid vesicles: comparison of $\mathrm{Na}, \mathrm{K}$ and $\mathrm{Na}$ only pumping mode. Biochim Biophys Acta 1023:81 90

Bibert S, Roy S, Schaer D, Horisberger JD, Geering K (2008) Phosphorylation of phospholemman (FXYD1) by protein kinases $\mathrm{A}$ and $\mathrm{C}$ modulates distinct $\mathrm{Na}, \mathrm{K}$ ATPase isozymes. J Biol Chem 283:476 486

Bossuyt J, Despa S, Han F, Hou Z, Robia SL, Lingrel JB, Bers DM (2009) Isoform specificity of the $\mathrm{Na} / \mathrm{K}$ ATPase association and regulation by phospholemman. J Biol Chem 284:26749 26757

Brown DA, Rose JK (1992) Sorting of GPI anchored proteins to glycolipid enriched membrane subdomains during transport to the apical cell surface. Cell 68:533 544

Cirri E, Katz A, Mishra NK, Belogus T, Lifshitz Y, Garty H, Karlish SJ, Apell HJ (2011) Phospholemman (FXYD1) raises the affinity of the human $\alpha 1 \beta 1$ isoform of $\mathrm{Na}, \mathrm{K}$ ATPase for $\mathrm{Na}$ ions. Biochemistry 50:3736 3748

Cohen E, Goldshleger R, Shainskaya A, Tal DM, Ebel C, leMaire M, Karlish SJ (2005) Purification of $\mathrm{Na}+, \mathrm{K}+$ ATPase expressed in Pichia pastoris reveals an essential role of phospholipid protein interactions. J Biol Chem 280:16610 16618

Cornelius F, Mahmmoud YA (2003) Functional modulation of the sodium pump: the regulatory proteins "Fixit". News Physiol Sci 18:119 124

Crambert G, Geering K (2003) FXYD proteins: new tissue specific regulators of the ubiquitous Na,K ATPase. Sci STKE 2003:RE1

Crambert G, Beguin P, Pestov NB, Modyanov NN, Geering K (2002a) $\beta \mathrm{m}$, a structural member of the $X$, K ATPase $\beta$ subunit family, resides in the ER and does not associate with any known X, K ATPase $\alpha$ subunit. Biochemistry 41:6723 6733

Crambert G, Fuzesi M, Garty H, Karlish S, Geering K (2002b) Phospholemman (FXYD1) associates with Na, K ATPase and regulates its transport properties. Proc Natl Acad Sci USA 99:11476 11481

de Pont JJHHM, van Prooijen van Eeden A, Bonting SL (1978) Role of negatively charged phospholipids in highly purified $\left(\mathrm{Na}^{+}+\mathrm{K}^{+}\right)$ATPase from rabbit kidney outer medulla. Biochim Biophys Acta 508:464 477

Despa S, Bossuyt J, Han F, Ginsburg KS, Jia LG, Kutchai H, Tucker AL, Bers DM (2005) Phospholemman phosphorylation mediates the beta adrenergic effects on $\mathrm{Na} / \mathrm{K}$ pump function in cardiac myocytes. Circ Res 97:252 259

Feschenko MS, Donnet C, Wetzel RK, Asinovski NK, Jones LR, Sweadner KJ (2003) Phospholemman, a single span membrane protein, is an accessory protein of $\mathrm{Na}, \mathrm{K}$ ATPase in cerebellum and choroid plexus. J Neurosci 23:2161 2169

Floyd RV, Wray S, Martin Vasallo P, Mobasheri A (2010) Differ ential cellular expression of FXYD1 (phospholemman) and FXYD2 (gamma subunit of Na,K ATPase) in normal human tissues: a study using high density human tissue microarrays. Ann Anat 192:7 16

Franzin CM, Gong XM, Teriete P, Marassi FM (2007) Structures of the FXYD regulatory proteins in lipid micelles and membranes. J Bioenerg Biomembr 39:379 383

Fuller W, Eaton P, Bell JR, Shattock MJ (2004) Ischemia induced phosphorylation of phospholemman directly activates rat cardiac $\mathrm{Na} / \mathrm{K}$ ATPase. FASEB J 18:197 199

Fuller W, Howie J, McLatchie LM, Weber RJ, Hastie CJ, Burness K, Pavlovic D, Shattock MJ (2009) FXYD1 phosphorylation in vitro and in adult rat cardiac myocytes: threonine 69 is a novel substrate for protein kinase C. Am J Physiol Cell Physiol 296:C1346 C1355

Garty H, Karlish SJ (2006) Role of FXYD proteins in ion transport. Annu Rev Physiol 68:431 459

Geering K (2005) Function of FXYD proteins, regulators of $\mathrm{Na}, \mathrm{K}$ ATPase. J Bioenerg Biomembr 37:387 392 
Geering K (2006) FXYD proteins: new regulators of Na K ATPase. Am J Physiol Renal Physiol 290:F241 F250

Geering K (2008) Functional roles of Na,K ATPase subunits. Curr Opin Nephrol Hypertens 17:526 532

Geering K, Beguin P, Garty H, Karlish S, Fuzesi M, Horisberger JD, Crambert G (2003) FXYD proteins: new tissue and isoform specific regulators of $\mathrm{Na}, \mathrm{K}$ ATPase. Ann $\mathrm{N}$ Y Acad Sci 986:388 394

Gloster J, Harris P (1969) The lipid composition of mitochondrial and microsomal fractions of human myocardial homogenates. Car diovasc Res 3:45 51

Habeck M, Cirri E, Katz A, Karlish SJ, Apell HJ (2009) Investigation of electrogenic partial reactions in detergent solubilized $\mathrm{Na}, \mathrm{K}$ ATPase. Biochemistry 48:9147 9155

Han F, Tucker AL, Lingrel JB, Despa S, Bers DM (2009) Extracellular potassium dependence of the $\mathrm{Na}^{+} \mathrm{K}^{+}$ATPase in cardiac myocytes: isoform specificity and effect of phospholem man. Am J Physiol Cell Physiol 297:C699 C705

Han F, Bossuyt J, Martin JL, Despa S, Bers DM (2010) Role of phospholemman phosphorylation sites in mediating kinase dependent regulation of the $\mathrm{Na}^{+} \mathrm{K}^{+}$ATPase. Am J Physiol Cell Physiol 299:C1363 C1369

Haviv H, Cohen E, Lifshitz Y, Tal DM, Goldshleger R, Karlish SJ (2007) Stabilization of Na+, K+ ATPase purified from Pichia pastoris membranes by specific interactions with lipids. Bio chemistry 46:12855 12867

Hughes E, Whittaker CA, Barsukov IL, Esmann M, Middleton DA (2011) A study of the membrane association and regulatory effect of the phospholemman cytoplasmic domain. Biochim Biophys Acta 1808:1021 1031

Jørgensen PL (1974) Isolation of $\left(\mathrm{Na}^{+}+\mathrm{K}^{+}\right)$ATPase. Methods Enzymol 32:277 290

Katz A, Lifshitz Y, Bab Dinitz E, Kapri Pardes E, Goldshleger R, Tal DM, Karlish SJ (2010) Selectivity of digitalis glycosides for isoforms of human Na,K ATPase. J Biol Chem 285:19582 19592

Lambert O, Levy D, Ranck JL, Leblanc G, Rigaud JL (1998) A new "gel like" phase in dodecyl maltoside lipid mixtures: implica tions in solubilization and reconstitution studies. Biophys $\mathrm{J}$ 74:918 930

Lifshitz Y, Lindzen M, Garty H, Karlish SJ (2006) Functional interactions of phospholemman (PLM) (FXYD1) with $\mathrm{Na}+$, $\mathrm{K}+$ ATPase: purification of $\alpha 1 / \beta 1 /$ PLM complexes expressed in Pichia pastoris. J Biol Chem 281:15790 15799

Lifshitz Y, Petrovich E, Haviv H, Goldshleger R, Tal DM, Garty H, Karlish SJ (2007) Purification of the human $\alpha 2$ isoform of $\mathrm{Na}, \mathrm{K}$ ATPase expressed in Pichia pastoris: stabilization by lipids and FXYD1. Biochemistry 46:14937 14950

Liu L, Askari A (2006) Beta subunit of cardiac $\mathrm{Na}^{+} \mathrm{K}^{+}$ATPase dictates the concentration of the functional enzyme in caveolae. Am J Physiol Cell Physiol 291:C569 C578

Liu L, Mohammadi K, Aynafshar B, Wang H, Li D, Liu J, Ivanov AV, Xie Z, Askari A (2003) Role of caveolae in signal transducing function of cardiac $\mathrm{Na}^{+} / \mathrm{K}^{+}$ATPase. Am J Physiol Cell Physiol 284:C1550 C1560
McLaughlin S (1977) Electrostatic potentials at membrane solution interfaces. Current topics in membranes and transport, vol 9. Academic Press, New York, pp 71144

Mishra NK, Peleg Y, Cirri E, Belogus T, Lifshitz Y, Voelker DR, Apell HJ, Garty H, Karlish SJ (2011) FXYD proteins stabilize Na,K ATPase: amplification of specific phosphatidylserine protein interactions. J Biol Chem 286:9699 9712

Morth JP, Pedersen BP, Toustrup Jensen MS, Sorensen TL, Petersen J, Andersen JP, Vilsen B, Nissen P (2007) Crystal structure of the sodium potassium pump. Nature 450:1043 1049

Palmer CJ, Scott BT, Jones LR (1991) Purification and complete sequence determination of the major plasma membrane substrate for cAMP dependent protein kinase and protein kinase $\mathrm{C}$ in myocardium. J Biol Chem 266:11126 11130

Pavlovic D, Fuller W, Shattock MJ (2007) The intracellular region of FXYD1 is sufficient to regulate cardiac $\mathrm{Na} / \mathrm{K}$ ATPase. FASEB J 21:1539 1546

Post LL, Schuel R, Schuel H (1988) Evidence that hatching enzyme of the sea urchin Strongylocentrotus purpuratus is a chymo trypsin like protease. Biochem Cell Biol 66:1200 1209

Presti CF, Jones LR, Lindemann JP (1985a) Isoproterenol induced phosphorylation of a 15 kilodalton sarcolemmal protein in intact myocardium. J Biol Chem 260:3860 3867

Presti CF, Scott BT, Jones LR (1985b) Identification of an endog enous protein kinase $\mathrm{C}$ activity and its intrinsic 15 kilodalton substrate in purified canine cardiac sarcolemmal vesicles. J Biol Chem 260:13879 13889

Schneeberger A, Apell H J (1999) Ion selectivity of the cytoplasmic binding sites of the Na,K ATPase: I. Sodium binding is associated with a conformational rearrangement. J Membr Biol 168:221 228

Schwartz AK, Nagano M, Nakao M, Lindenmayer GE, Allen JC (1971) The sodium and potassium activated adenosinetriphos phatase system. Methods Pharmacol 1:361 388

Shinoda T, Ogawa H, Cornelius F, Toyoshima C (2009) Crystal structure of the sodium potassium pump at 2.4 a resolution. Nature 459:446 450

Silverman BZ, Fuller W, Eaton P, Deng J, Moorman JR, Cheung JY, James AF, Shattock MJ (2005) Serine 68 phosphorylation of phospholemman: acute isoform specific activation of cardiac $\mathrm{Na} /$ K ATPase. Cardiovasc Res 65:93 103

Smart EJ, Graf GA, McNiven MA, Sessa WC, Engelman JA, Scherer PE, Okamoto T, Lisanti MP (1999) Caveolins, liquid ordered domains, and signal transduction. Mol Cell Biol 19:7289 7304

Sweadner KJ, Rael E (2000) The FXYD gene family of small ion transport regulators or channels: cDNA sequence, protein signature sequence, and expression. Genomics 68:41 56

Teriete P, Franzin CM, Choi J, Marassi FM (2007) Structure of the $\mathrm{Na}, \mathrm{K}$ ATPase regulatory protein FXYD1 in micelles. Biochem istry 46:6774 6783

Walaas SI, Czernik AJ, Olstad OK, Sletten K, Walaas O (1994) Protein kinase $\mathrm{C}$ and cyclic AMP dependent protein kinase phosphorylate phospholemman, an insulin and adrenaline regu lated membrane phosphoprotein, at specific sites in the carboxy terminal domain. Biochem J 304(Pt 2):635 640 